\title{
Communication of Context in Multi-Echelon Information Exchange Environments
}

\author{
Authors: \\ Heather M. Oonk \\ hmoonk@pacific-science.com \\ Pacific Science \& Engineering Group, Inc. \\ 9180 Brown Deer Road \\ San Diego, CA 92121 \\ 858-535-1661 - office \\ 858-535-1665 - fax \\ Ronald A. Moore \\ ramoore@pacific-science.com \\ Pacific Science \& Engineering Group, Inc. \\ 9180 Brown Deer Road \\ San Diego, CA 92121 \\ 858-535-1661 - office \\ 858-535-1665 - fax \\ Jeffrey G. Morrison \\ jmorriso@spawar.navy.mil \\ jeff.morrison@navy.mil \\ SPAWAR Systems Center, San Diego \\ 53560 Hull Street \\ San Diego, CA 92152-5000 \\ 619-553-9070 - office \\ 619-553-9072 - fax
}

\section{Point of Contact:}

Heather M. Oonk

hmoonk@pacific-science.com

Pacific Science \& Engineering Group, Inc.

9180 Brown Deer Road

San Diego, CA 92121

619-553-9070 - office

619-553-9072 - fax 


\title{
Communication of Context in Multi-Echelon Information Exchange Environments
}

\author{
Heather M. Oonk \& Ronald A. Moore \\ Pacific Science \& Engineering Group, Inc. \\ 9180 Brown Deer Rd., San Diego, CA 92121 \\ Jeffrey G. Morrison, Ph. D. \\ Space and Naval Warfare Systems Center, San Diego \\ SPAWAR Systems Center, San Diego \\ 53560 Hull Street \\ San Diego, CA 92152-5000
}

\begin{abstract}
In fast-paced, distributed, multi-echelon, collaborative environments such as those experienced by the United States military during Operations Enduring Freedom and Iraqi Freedom, task performance very often depends on effective and efficient information exchange. One way to facilitate information exchange is to ensure that information producers and consumers develop a thorough shared "situation context." Unfortunately, developing such a shared understanding of situation context is extremely difficult in these types of environments. This paper discusses a series of experiments that investigated methods of communicating context to information producers, and the impact this had on task performance. The results of these studies are intended to facilitate the design and development of tools to aid information producers and consumers in quickly and easily building shared situation context, and developing useful, usable information products based on this shared understanding. This paper reports the methods and results of the experiments conducted. The experiment results highlight important issues associated with building a shared situation context among information producers and consumers, and provide important insights necessary to develop tools to facilitate efficient and effective information exchange.
\end{abstract}

\section{Introduction}

A fundamental aspect of Network-centric command decision-making is the exchange of information so as to share knowledge and support decision making. In decision-making environments, information is often being exchanged among individuals and teams at different echelons, working on different schedules in distributed global locations. In such an environment, information producers will have varying degrees of knowledge about the people with whom they are sharing information, and this can adversely affect information exchange. Conventional wisdom would suggest that we simply build aids to assist people in understanding each others' needs, yet as scientists and technologists we have a poor understanding of which aspects of knowledge about the people with whom one is 
collaborating impact the effectiveness of sharing information. This issue is becoming more critical as the military increasingly moves to a network-centric concept of operations. Operations in modern distributed, multi-echelon environments are increasingly reliant on advanced collaboration technologies which have made it possible to transfer large amounts of information quickly to almost any location. However these technologies do not necessarily facilitate the exchange of the right information. The study described here is one of a series being conducted to look at strategies for taking best advantage of the capabilities presented by network-centric operations and identifying strategies to mitigate potential pitfalls

In any collaborative environment, optimal performance depends on information exchange being as effective and efficient as possible. Information exchange, as it is discussed here, refers to the process of producing information for, or consuming information from, a shared information space. Participants in the information exchange process are therefore, producers, consumers, and often, both. Information exchange is effective if producers are creating all of the information that consumers need and consumers are accessing all the information they need, i.e.,

Effectiveness $=$ Relevant information produced and consumed All relevant information in the information space

Information exchange is efficient if producers are not creating information that is extraneous to the consumers' tasks, i.e.,

$$
\text { Efficiency }=\quad \begin{aligned}
& \text { Irrelevant information produced and consumed } \\
& \text { All irrelevant information in the information space }
\end{aligned}
$$

\section{Information Exchange Problems}

Based on previous cognitive task analyses and evaluations of collaboration tool use in distributed multi-echelon environments (e.g., Moore \& Averett, 1999; Oonk, Smallman, Moore, \& Morrison, 2001; Rogers, Oonk, Moore, \& Morrison, 2002; Smallman, Oonk, \& Moore, 2001) we have identified two problems that contribute to inefficient and ineffective information exchange:

1. Poor understanding of consumer information: Tasks and information requirements. Military decision makers and their staffs consistently state that understanding each other's tasks, intentions, priorities, and information requirements are important but that this understanding does not always exist. Information producers often do not understand what information the consumer needs and how he will be using that information.

2. Requirement for tailored information. Military decision makers have also indicated the need for information products that are customized to meet their own specific needs. Such customization is not so easily accomplished in a multiechelon/multi-consumer environment. When the production of customized information has been available, it has frequently been created with the requirements of a single consumer in mind. However, other consumers are often required to access and use the product even though it has not been tailored to these consumers' needs. 
The identification of these issues underscores an important requirement in information exchange environments: communication of context. In order to alleviate such problems, it is necessary to provide producers with improved, shared understanding of "situation context," with respect to those consumers for whom they create information. This paper discusses a series of experiments in which we investigated methods of communicating situation context to information producers. Specifically, previous and ongoing experiments and evaluations have examined 1) what information should be displayed, and 2) how best to display that information.

\section{The importance of context.}

The understanding of context by individuals is related to the state of their evolving mental models. Mental models are internal knowledge structures held by individuals that allow them to make sense of their surroundings (Klimoski \& Mohammed, 1994). Mental models provide individuals with a context within which to make inferences about, understand relationships between and attribute meaning to events in their environment, as well as make predictions about the future (Rouse \& Morris, 1986). Recently, the idea of "shared mental models" - such representations shared across members of a group of individuals - has been used to help explain team behaviors and performance (e.g., Cannon-Bowers, Salas \& Converse, 1993, Mathieu, Goodwin, Heffner, Salas, \& CannonBowers, 2000, Salas, Cannon-Bowers, \& Blickensderfer, 1997). The degree to which these models are shared is believed to be linked to team performance, team effectiveness, adaptation, and coordination (Cannon-Bowers, et al., 1993). Because appropriate mental models enable team members to form accurate explanations and expectations about the task, the environment, and each other, the quantity and quality of information exchange should change with the quality of the mental model (and vice versa) (Caldwell \& Everhart, 1998; Mathieu et al., 2000).

\section{Communicating context.}

Unlike most studies in the literature that measure the overlap between team members' mental models and their relationship to team performance, our research attempts to manipulate mental models and look at the effect on team performance. We do this in order to understand the relationship between shared mental models and the effectiveness and efficiency of information exchange (Oonk, Schermerhorn, Glaser, \& Manes, 2003).

In order to manipulate mental models in an experimental setting, one must have an understanding of what aspects of the mental model are important - in other words, what aspects of the mental model should be shared and communicated to team members. Mathieu et al. (2000) identified three categories of mental models: 1) Shared understanding of technology used by team members, its functioning and control and how other team members interact with it; 2) Shared understanding of the team task, strategies used to accomplish it, environmental conditions, and potential problems; 3) Shared understanding of interaction between team members, information flow, roles and role relationships, information sources and knowledge, and skills of team members. This third type of mental model comprises the features that we believe define "situation context."

The experiments described in this paper investigated the effects of presenting different aspects of situation context to information producers. Based on previous analyses and 
discussions with information producers and consumers, we identified four components of situation context that could potentially be communicated.

- Mission (What the organization is doing): Many times information producers are only aware of the general context under which their team or organization is operating. They understand the mission or high-level goals of the organization but not the specific roles that the consumers with whom they share information play within this mission. Without this knowledge, producers must make assumptions, based on prior experience, about what consumers are doing and what information they need to support them.

- $\quad$ Stated information requirements (What I need): Information consumers may provide producers with a list of the information requirements that consumers believe they need to conduct their tasks. This gives producers more specific information about consumers' needs than just the mission information. However, a problem with the use of such a list is that it assumes that consumers know everything that they need (as well as what producers are able to provide them) and are able to communicate that information. Many times producers have information that consumers need of which they are not aware. Producers are unlikely to share such information if they don't know why consumers need it.

- Current task (What I'm working on): Information consumers may provide producers with a list of the current tasks on which they are working. A benefit of presenting task to producers is that they will be more likely to share information with consumers that they believe will be useful to their tasks, whether it was explicitly asked for or not. However, this assumes that producers have a certain level of knowledge about what the tasks entail and what information is necessary to support them.

- Information requirements and task (What I need and what I'm working on). Based on the limitations of the methods listed above, the intuitively optimal method is to communicate both consumers' tasks and information requirements. This would make it more likely that information that consumers believe that they need and that producers believe the consumers need would be shared. However, this amount of information may be unnecessary and it may even be associated with increased workload for producers.

In two experiments, we examined how well each of the above methods of communicating consumer information supported information production. Participants played the role of an information producer in a multi-echelon, multi-consumer military organization. After reviewing a set of information items, they were given information about the consumer either 1) the overall mission, 2) the mission and the consumer's stated information requirements, 3) the mission and the consumer's tasks, or 4) the mission, the consumer's information requirements, and tasks. Based on this information, participants sorted each of the information items based on how relevant they believed its content was to the consumer (choices were relevant, somewhat relevant, or not relevant). In each experiment, participants performed the sort task twice, using two independent sets of information items. In Experiment 1, they sorted the items for a different consumer each time. In Experiment 2, they sorted the items for one consumer in one block, and for two consumers in the other. Participants were given the consumer information for both 
consumers in the two consumer block and they were instructed to perform the sort task as if they were creating an information product for both consumers. This manipulation allowed us to examine how useful an information product created for multiple-consumers would be for each of the individual consumers.

We focused on participants' performance, in terms of effectiveness and efficiency. We define effectiveness as how well the participants performed at deciding which information was relevant. We define efficiency as how well the participants performed at deciding which information was not relevant. Performance was based on the overlap between participants' decisions and ratings provided by military subject matter experts (SMEs) who had assumed the role of the consumer whom participants were sorting for. We used both accuracy (proportion correct) and signal detection measures (sensitivity and response bias) to define performance. In order to look at the effects of tailoring information (i.e., the cost to one consumer accessing information products created with another consumer's information needs in mind), we also looked at the overlap between participants' decisions and ratings provided by SMEs who had assumed the role of the consumer whom the participants were not sorting for.

\section{Experiment 1}

\section{Method}

Participants. Thirty-two participants each served in a single 2-hour session. Most $(n=$ 24) were students from a local university or members of the community who were paid for their participation. The rest were employees of the facility at which data were collected.

Stimuli. Two sets of 40 information items, Scenarios A and B, were compiled. The items contained content related to various degrees to an overall Humanitarian Assistance Disaster Relief (HA-DR) mission. They consisted of pictures, text information, tables, weather and timeline charts, and tactical or other maps. Several handouts were also created for use as visual aids. These were: 1) a text copy of the scenario and map highlighting scenario locations; 2) a chart of the organizational structure and information flow between consumers and producers; and 3) consumer information handouts (one for each consumer in each display condition) that were used to present information about the consumer in the form of bulleted lists.

Procedure. At the beginning of the experiment, participants were introduced to the organization and HA-DR scenario. They were told that they were part of a multi-level military organization consisting of information consumers and producers conducting a fictional mission. Appropriate visual aids were provided. They were told that they would be playing the role of one of the information producers.

Each experimental block consisted of two phases: a "Review" Phase and a "Sort" Phase. During the Review Phase, participants were given 25 minutes to view the information items presented in a list. Participants were told to spend the time becoming familiar with the content of the information items and gain situation awareness about the mission. To review an item, participants double-clicked on it with the mouse. They could view the 
items as many times and for as long as they wished but were encouraged to attempt to view all items in the list in the given time.

Following the Review Phase, participants were given information about the consumer for whom they would be sorting information. This varied, dependent on which of the four "consumer information" display conditions participants were assigned to. These display conditions were:

- Mission Only (M Only): participants received information about the overall mission being conducted by their organization.

- Mission+Information $(M+I)$ : in addition to the mission information, participants were provided a list of information that they were told the consumer stated that they needed.

- Mission+Task $(M+T)$ : in addition to the mission information, participants were provided a list of tasks that they were told the consumer was currently working on.

- Mission+Information+Task $(M+I+T)$ : in addition to the mission information, participants were provided a list of information requirements and a list of the consumer's current tasks.

All participants first read information about the mission. They were then told which consumer (either the Commander, Joint Task Force (CJTF) or his Deputy Operations Officer (DOO)), they would be sorting information for in that experimental block. Participants in the M Only condition then began the Sort Phase of the experiment. Participants in the other 3 conditions were given additional information about the consumer before beginning the Sort Phase.

During the Sort Phase, participants sorted each information item according to whether they believed the content of the information item was "relevant," "not relevant," or "somewhat relevant" based on what they understood about the consumer's specific task. It was stressed to participants that some information was relevant to the overall HA-DR mission but not necessarily to the consumer's specific task. Participants sorted the information by dragging and dropping the items with the mouse into one of three windows, labeled "Relevant", "Somewhat Relevant," or "Not Relevant," on the right side of the data collection interface. Participants were given 15 minutes to perform the sort task.

Design. Eight participants served in each of the four consumer information display conditions (M Only, M+I, M+T, M+I+T). Each participant served in two separate blocks and in each block they reviewed information from a different information set (Scenarios A or B) and sorted information for a different consumer (the CJTF or DOO). The pairings between consumer and information set (e.g., sorting Scenario A for the CJTF) and the order of blocks were counterbalanced.

In order to examine the effects of tailored content, i.e., how useful an information product created for one consumer is when it is accessed by another consumer, the experimental design included another variable: correspondence. We compared performance across two levels of correspondence: in the Match condition, we based the performance measures on 
the ratings made by the same consumers that participants believed they were sorting for (e.g., the CJTF ratings for the CJTF consumer condition); in the Mismatch condition we based them on the ratings made by the other consumer (e.g., the DOO ratings for the CJTF consumer condition).

Ratings. Five SMEs served as raters. All of them had previously served in the military (mean years of service $=18.1, \mathrm{SD}=8.6$, Range $=9.5-30)$ and were currently professionals working in military contexts (mean years of service $=10.8, \mathrm{SD}=5.3$, Range $=5$ - 19). Ratings were collected from the raters with the same Review/Sort task and tool used by the experimental participants. SMEs were given the information provided in the $\mathrm{M}+\mathrm{I}+\mathrm{T}$ condition, i.e., all information about the consumer whose role they were asked to assume. ${ }^{1[1]}$

\section{Results and Discussion}

Three performance measures were analyzed, based on participants' degree of concordance with the SME ratings of the relevance of information items. These were: 1) Accuracy: Proportion correct for all items and for each of the three rating/sorting categories, e.g., proportion of items rated as relevant by the consumers that were sorted as relevant by participants; and two signal detection measures based on each participant's mean hit and false alarm rates for all items and for each of the three rating/sorting categories: 2) Sensitivity - $d$ 'values; 3) Response bias $-\beta$ values. After analyzing performance over all items, we analyzed Relevant and Not Relevant items separately. These last analyses allowed us to evaluate participants' ability to make two important and complementary types of decisions that relate to:

1. Effectiveness: giving consumers access to useful content (Relevant items)

2. Efficiency: not giving access to content that is not useful (Not Relevant items)

Overall Performance. Not surprisingly, communicating situation context related to the tasks and information requirements of a specific consumer allows producers to create an information product that meets that consumer's needs. However, this product will be less useful to other consumers, who are working on different tasks and have different requirements. As expected, performance, as measured by both accuracy (proportion correct) and sensitivity ( $d$ '), was higher when it was based on the ratings made by the consumer that was being sorted for (Match condition) than when based on the other consumer's ratings (Mismatch) (.66 vs .56, $F(1,28)=40.39, p<.0001$ for accuracy; 1.33 vs. .94, $F(1,28)=34.15, p<.0001$ for sensitivity).

Deciding what is relevant: effectiveness of information exchange: Mean accuracy, sensitivity, and response bias for Relevant items are shown in Figure 1. The results indicate that task information is the most important aspect (of those examined) of situation context in supporting effective information exchange. Producers who know the consumer's task perform better when deciding what is relevant to the consumer than

\footnotetext{
${ }^{1[1]}$ Because we base performance on the SME ratings (as the "true" ratings), items rated as "relevant", "not relevant" and "somewhat relevant" are henceforth referred to as "Relevant items", "Not Relevant items", and "Somewhat Relevant items", respectively.
} 
those who only know the overall mission or are provided with a list of information requirements.
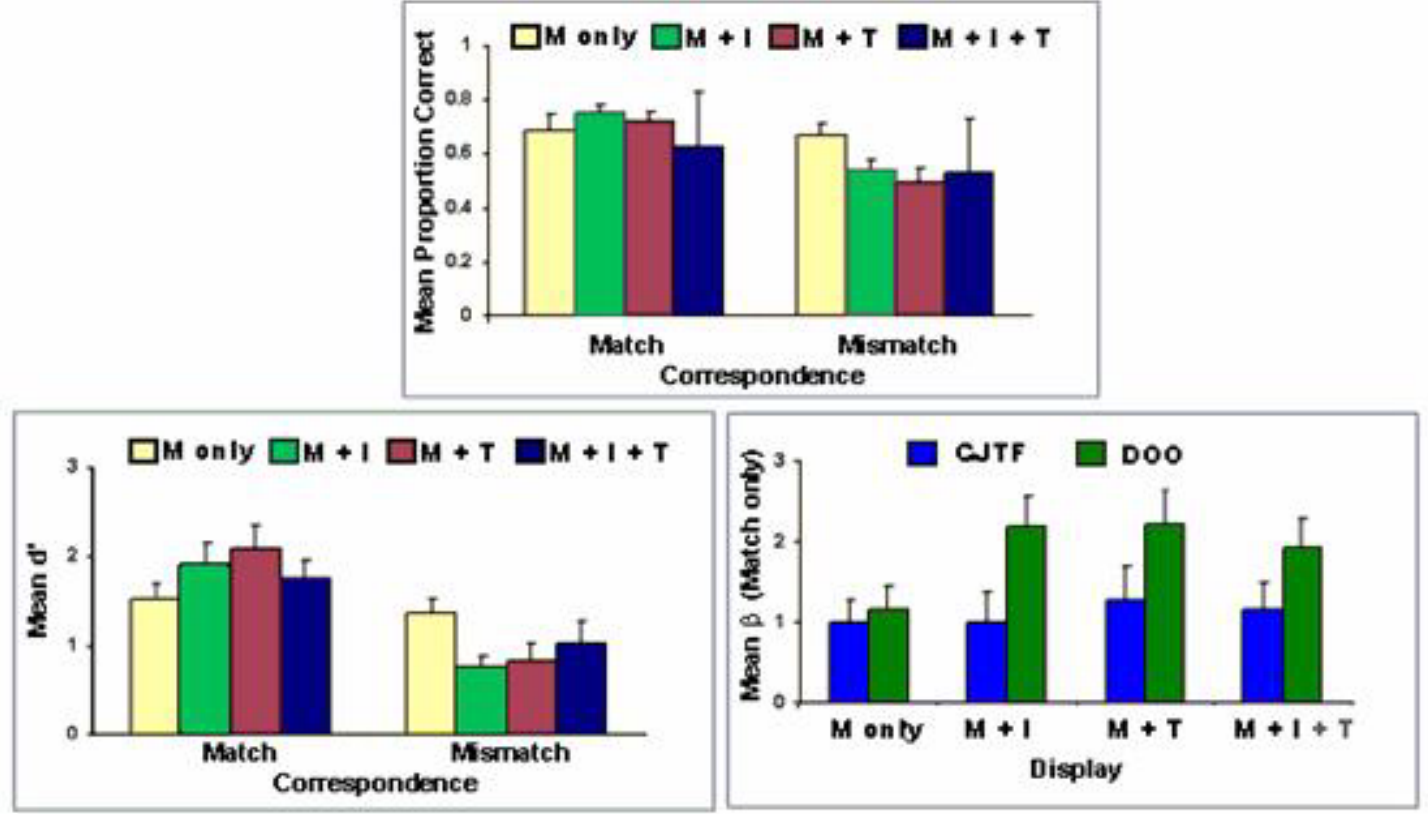

Figure 1. Mean accuracy (top), sensitivity (bottom left) and response bias (bottom right) for Relevant items in Experiment 1. Note, $\mathrm{M}=$ Mission, $\mathrm{I}=$ Information Requirements, $\mathrm{T}=$ Task.

Performance was better in the Match condition than Mismatch condition, as measured by sensitivity $(F(1,28)=31.01, p<.0001)$, and accuracy $(F(1,28)=26.03, p<.0001$. $)$ In the Match condition, participants who were given information about the consumer's task and/or information requirements performed better when deciding whether an information item was relevant to the consumer's task than those who were given just the overall mission information. Sensitivity values ( $d$ 's) were highest with the M+T and M+I displays and lowest with the $\mathrm{M}$ Only display (although this difference was not statistically significant, $F(3,28)=1.07, p=.37)$. The reverse pattern was found for the Mismatch condition: participants in the M Only conditions were more accurate $(F(3,28)$ $=5.10, p=.01$ ) and exhibited higher $d$ ' values than those in the other conditions (although this difference was not statistically significant, $F(3,28)=1.50, p=.24$ ). This suggests that, if an information producer is tailoring an information product for a particular consumer, information exchange will be more effective with respect to that consumer (i.e., they will be more likely to get the information that they need) but at a cost to the other consumers. Information exchange would actually be more ineffective with respect to other consumers, i.e., they would be less likely to get the information they need to perform their task.

Deciding what is not relevant: efficiency of information exchange: Mean accuracy, sensitivity, and response bias for Not Relevant items are shown in Figure 2. The results indicate that task information is also the most important aspect (of those examined) of situation context in supporting efficient information exchange. 

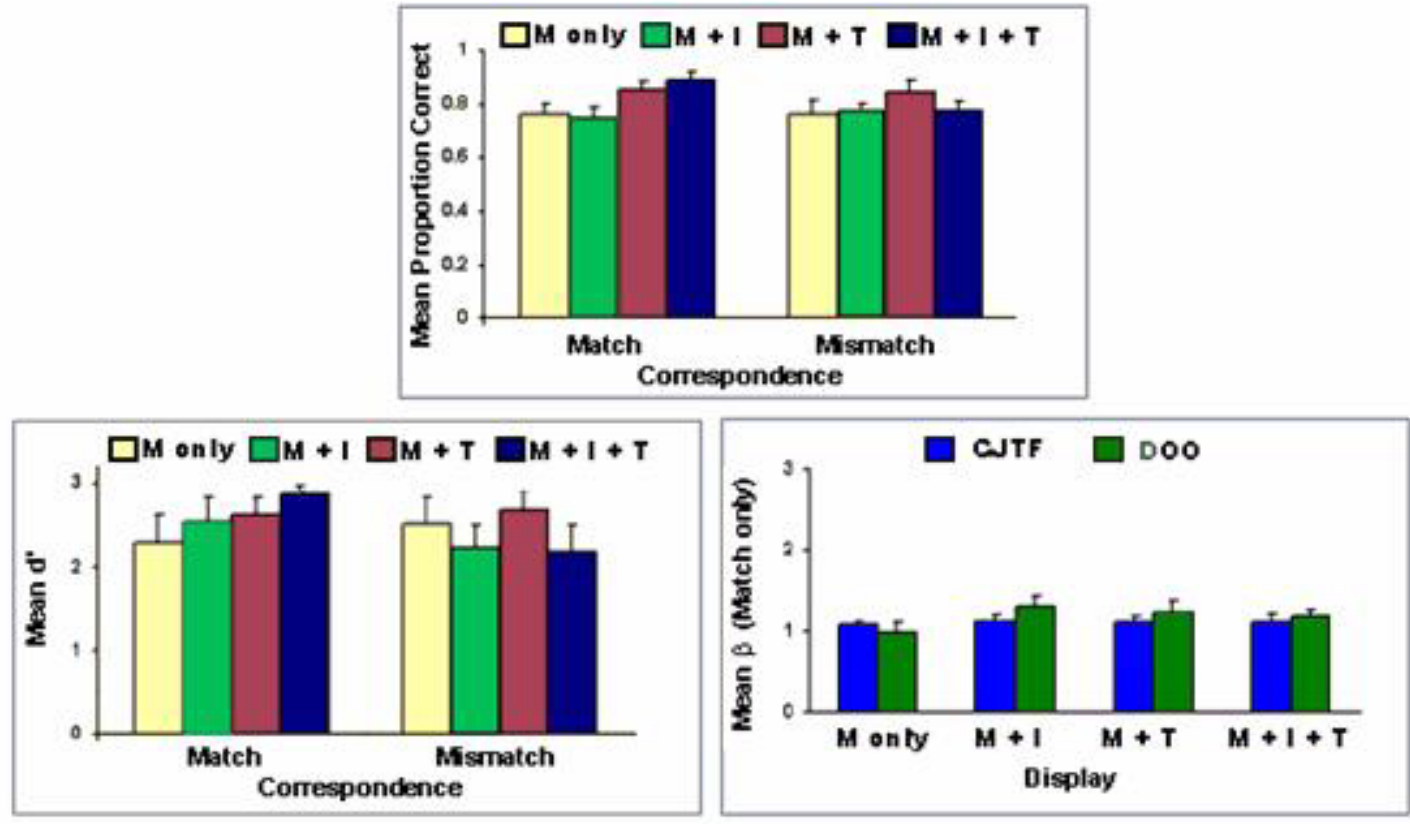

Figure 2. Mean accuracy (top), sensitivity (bottom left) and response bias (bottom right) for Not Relevant items in Experiment 1. Note, $\mathrm{M}=$ Mission, $\mathrm{I}=$ Information Requirements, $\mathrm{T}=$ Task.

Participants who were given information about the consumer's task performed better when deciding whether an information item was not relevant to the consumer's task than those who were given just the overall mission information or the mission information plus the consumer's information requirements (for accuracy, $F(3,28)=24.33, p<.0001$ ). There was no difference in performance across display conditions in the Mismatch condition This suggests that, if an information producer is tailoring an information product for a particular consumer based on their understanding of the consumer's task, information exchange will be more efficient for that consumer (i.e., it will be less likely that that consumer will be given access to irrelevant information), with no cost to the other consumers.

\section{Experiment 2}

Although the results of experiment 1 revealed patterns of performance as a function of display condition that were similar across the different analyses, the results were not very robust (statistically). This may have been due to a lack of understanding of or focus on the part of participants on their role as an information producer, i.e., that the outcome of their sorting behavior would be an information product used by the consumer. The purpose of Experiment 2 was twofold: 1) We wanted to replicate the findings of Experiment 1, where participants sorted for a single consumer; 2) We were interested in assessing what differences there might be in information production when producers had multiple consumers. The task in the first part of Experiment 2 was almost identical to that in the previous experiment except that we changed the instructions slightly, increasing the emphasis on the participant's role as an information producer to obtain more powerful 
results. Specifically, we modified the operational definitions of "relevant," "somewhat relevant," and "not relevant."

Second, we were interested in the difference in performance when producers had multiple consumers as compared to one. Therefore, in the second part of Experiment 2 participants were given information about both consumers. The change in role definitions described below, which emphasized information production, facilitated the explanation of the multi-consumer situation to participants - they were told to consider that the information product that resulted from their sort would be accessible to both consumers.

\section{Method}

Participants. Thirty-two participants each served in a single 2-hour session. Most (28) were students from a local university or members of the community who were paid for their participation. The remaining participants were employees of the facility at which the data were collected.

Stimuli. The stimuli used were the same as in Experiment 1.

Procedure. The procedure was the same as in Experiment 1, with the following exceptions.

During training, the definitions of the three sorting categories were changed slightly to emphasize the task of information production. Changes were made for two reasons:

1. To encourage participants to think about how the outcome of the sort task might result in information product.

2. To facilitate the explanation to participants in the Two Consumer condition that they would be creating one information product to be used by two people.

Prior to the beginning of the Sort Phase, participants read information about the mission. They were then told which consumer(s) they would be sorting information for during that experimental block, the CJTF, DOO, or both. In blocks when participants sorted for two consumers they were given handouts for each, depending on the display condition in which they served.

Design. Eight participants served in each of the four consumer information display conditions. Each participant served in two separate blocks and, in each, reviewed information from a different information set. In one block, participants sorted information for one consumer (Single Consumer condition) and in the other they sorted for two consumers (Two Consumer condition). Half of the participants sorted information for the CJTF in the Single Consumer condition and half sorted for the DOO. The pairings between number of consumers and information set and the order of blocks were counterbalanced.

\section{Results and Discussion}

One vs. Two Consumers. The results suggest that an information product created based on information about more than one decision maker, will be less useful to each of those decision makers than would a product created based on each of their own tasks and information requirements. In general, accuracy at sorting items as relevant was higher when participants sorted for one consumer (based on that particular consumer's ratings) 
than when they sorted for two consumers (based on each of the two consumer's ratings). This result, however, was only found when the single consumer was the CJTF and when it was compared to the two consumer condition based on the DOO ratings (post hoc $\mathrm{p}<$ $.0125, F(6,48)=2.41, p=.04$ for the Number of Consumer X Consumer X Display interaction). This suggests that participants may have biased their behavior in the two consumer conditions toward the CJTF's needs, regardless of whether the DOO would also be using the product based on the sort. This is not surprising, given that the CJTF was at the "top" of the organization and participants may have felt his needs should be given higher weight than those of his subordinate. Sensitivity was also higher for sorting items as relevant when participants sorted for one consumer $\left(d^{\prime}=1.74\right)$ than when they sorted for two consumers (1.50 when based on CJTF ratings, 1.16 when based on DOO ratings), $F(2,56)=3.03, p=.06$.

The results also suggest that producers may be more likely to worry about "missing" important information when creating an information product for more than one consumer, and would be more likely to provide information that was not relevant. Response bias was generally lower when sorting relevant items for two consumers than one $(F(2,48)=$ $6.6, p<.01)$, but only for participants that sorted for the $\operatorname{DOO}(F(2,48)=8.63$ for the interaction, $p<.01$ for the , post hoc $p<.0125)$, indicating that participants were more likely to sort an item as relevant if two consumers might access it. For sorting not relevant items, response bias was lower when sorting items for one consumer, but only when the two consumer performance was based on DOO ratings $(F(1,24)=4.52, p=$ $.04)$. The reversal in the patterns of results for sorting the two categories suggests that participants favored effectiveness over efficiency in the two consumer condition. Participants may be concerned about missing relevant information in an information product if they believe more consumers, or just the CJTF, would have access to it.

Single Consumer.

Overall. We again obtained results that suggest that customizing an information product based on a specific consumer's information causes that product to be less useful to others, who might access it but have different tasks and information requirements. As in Experiment 1, performance was better when it was based on the consumer for whom participants were sorting than when it was based on the other consumer $(F(1,24)=8.31$, $p<.01)$.

Deciding what is relevant: effectiveness of information exchange: Mean accuracy, sensitivity, and response bias for Relevant items are shown in Figure 3. In contrast to the previous experiment, where the results suggested that task information was the most important aspect to effective information production, the results of Experiment 2 suggest that producers will be most effective if they are communicated the consumer's task and information requirements. The $\mathrm{M}+\mathrm{I}+\mathrm{T}$ display supported the most effective information sorting in the Match condition; participants who were given both the consumer's task and information requirements performed best when sorting items as relevant when their performance was based on the consumer that they sorted for $(F(3,24)=4.09, p=.02$, for accuracy; $F(3,24)=2.5, p=.08$, for sensitivity). However, as in Experiment 1, there was a cost when performance was based on the other consumer when participants were given 
consumer task and/or information requirements relative to just the mission for sorting relevant items only $(F(3,24)=2.6, p=.08$, for sensitivity $)$.

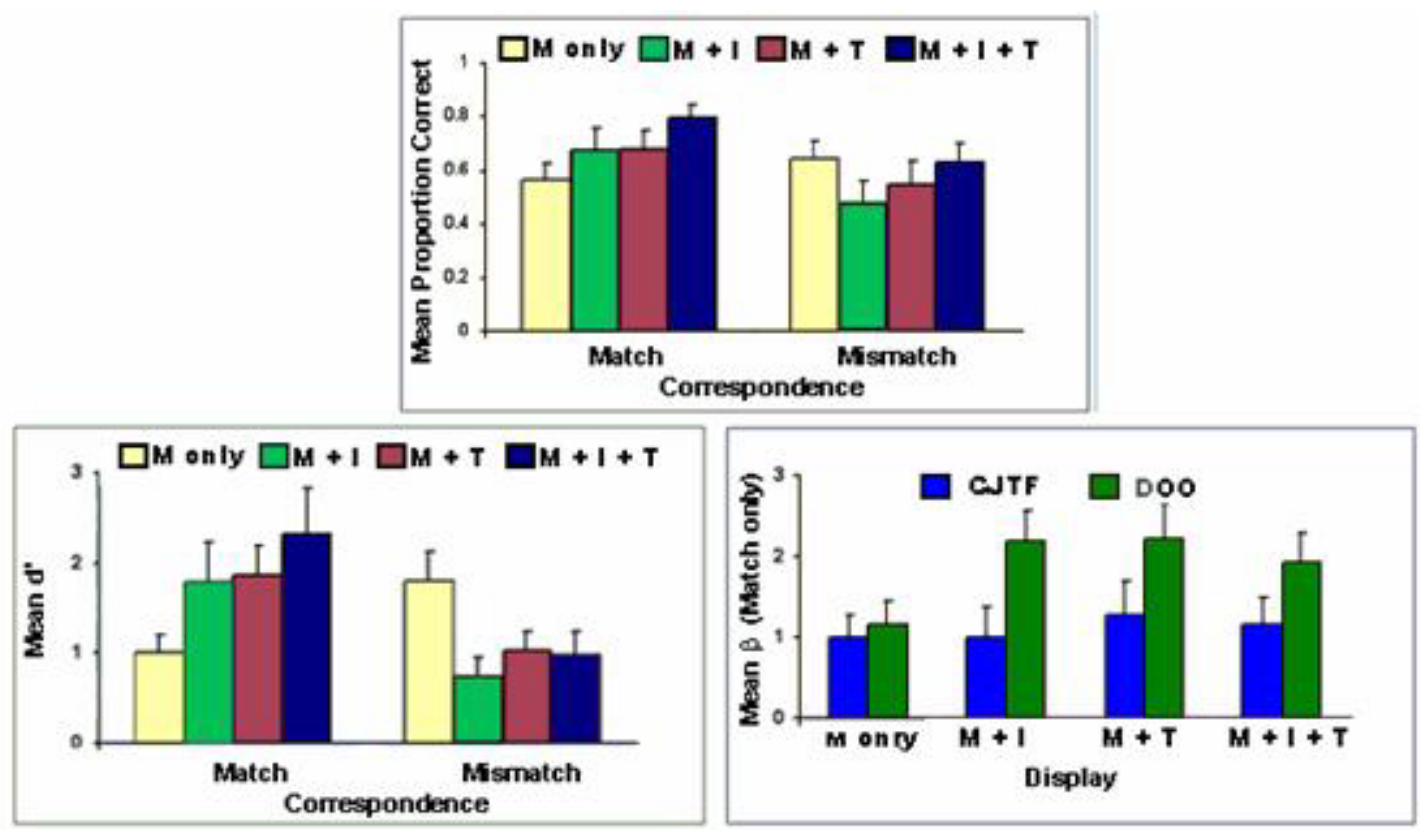

Figure 3. Mean accuracy (top), sensitivity (bottom left) and response bias (bottom right) for Relevant items in the Single Consumer condition of Experiment 2. Note, $\mathrm{M}=$ Mission, $\mathrm{I}=$ Information Requirements, $\mathrm{T}=$ Task.

Deciding what is not relevant: efficiency of information exchange: Mean accuracy, sensitivity, and response bias for Not Relevant items are shown in Figure 4. The results suggest that producers will be most efficient if they are communicated the consumer's task and information requirements. The $\mathrm{M}+\mathrm{I}+\mathrm{T}$ display supported the most efficient information sorting in the Match condition - participants who were given both the consumer's task and information requirements performed best when sorting items as not relevant when their performance was based on the consumer that they sorted for (although this difference was not statistically significant). 


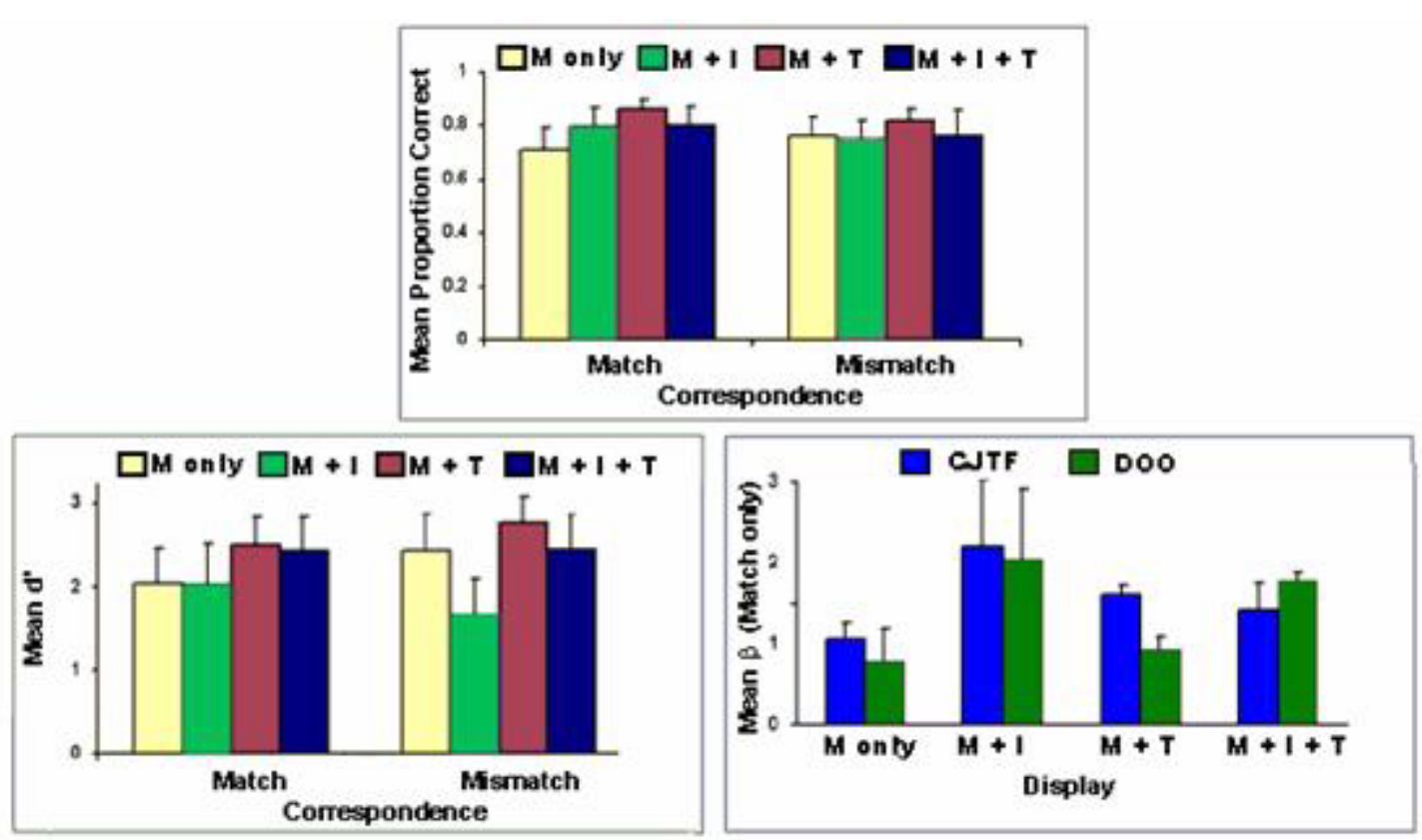

Figure 4. Mean accuracy (top), sensitivity (bottom left) and response bias (bottom right) for Not Relevant items in the Single Consumer condition of Experiment 2. Note, $\mathrm{M}=$ Mission, $\mathrm{I}=$ Information Requirements, $\mathrm{T}=$ Task.

Two Consumers. The results suggest that, when it is necessary for producers to create an information product for more than one consumer, the same information about task and information requirements of all the consumers should be provided to them. When participants sorted information for use by two consumers, patterns of performance as a function of display condition were generally the same as when they sorted for one consumer. Participants performed best when sorting items as both relevant and not relevant when they were given the consumer's mission, task and information requirements $(\mathrm{M}+\mathrm{T}+\mathrm{I})$ and worst when they were given the mission information only.

The findings of Experiment 2 are important for several reasons:

1. They replicate the results of Experiment 1 that demonstrated the cost of customizing information products in multi-consumer environments. Creating an information product based on knowledge about a single consumer will make it more useful to that consumer. However, other consumers, with different tasks and information requirements, will find it to be less useful than a more general, missionoriented product.

2. They contrast with the results of Experiment 1, where only task information was indicated as necessary to support effective and efficient information exchange, by suggesting that producers should be displayed both consumer task and consumer information requirements. This discrepancy in results is surprising, given that the participants' task in the Single Consumer condition was virtually identical to the task in Experiment 1, and they suggest that further investigation is necessary.

3. They extend the results of Experiment 2 in a multi-consumer situation and suggest that: 
a. Information products created for more than one consumer will be less useful to each of those decision makers than would a product created based on each of their own tasks and information requirements.

b. If multi-consumer information products are necessary, the tasks and information requirements of all consumers should be communicated to the producer.

\section{General Discussion}

The results suggest that, in order to support the most effective and efficient information exchange, producers should have access to the tasks consumers are performing, and what information requirements support that task, in addition to the general context or mission. The results highlight the importance of maintaining a shared understanding of the situation, roles, responsibilities and information requirements that is highlighted in the shared mental model and transactive memory literatures (e.g., Mathieu et al., 2000, Moreland, 1999), in studies of military supervisory systems and policies (e.g., Shattuck \& Woods, 1997), and analysis of military command and control environments (e.g., Oonk et al., 2000).

The results also have implications for customization of information products in multiconsumer environments, suggesting that there is a tradeoff between effectiveness and efficiency. If the emphasis were only to support the most efficient information exchange in such an environment, i.e., preventing consumers from accessing irrelevant information at risk of some consumers not getting everything they need, then information producers should be given information about the requirements of and tasks being performed by just one of the consumers. However, giving producers information about just a single consumer might be a detriment if it is important to have effective information exchange i.e., for all consumers to get the information they need. If the emphasis is the support of effective information exchange, then information about all consumers should be displayed. Unfortunately, given the large number of potential consumers, this is simply not feasible. Of course, practically speaking it is unlikely that the military will ever focus on efficiency or effectiveness alone; rather it is more likely that a balance will always have to be struck between the two and that a sensitivity to this issue will have to be addressed in future business practices and technologies to minimize the effect highlighted by the experiment results.

An issue related to customization of information products, especially in hierarchical environments like the military, is that of consumer "status." Participants in the experiments biased their behavior towards the consumer needs of the Commander over that of his Deputy, who had a lower position in the organization. This finding is intuitive and consistent with others in the literature (Heacox, Gwynne, Kelly, \& Sander, 2000; Torrance, 1955, as cited in Milanovich, Driskell, Stout, \& Salas, 1998), where higherstatus team members have been shown to have more influence on other team member's decision making than lower-status members. This tendency should be taken into consideration when deciding what information about consumers is communicated to producers. 
The results also have implications for the design of tools and displays that communicate situation context in multi-echelon, multi-consumer collaborative environments - and thus promote shared understanding and synchronized mental models. Our findings, however, suggest further questions and issues exist with respect to how to display situation context to information producers. These issues include:

- The breadth of information that is displayed. It is not practical to communicate all missions, tasks, and information requirements of all consumers in most multiconsumer environments and doing so could make the display less usable, causing information overload. Several questions are related to this issue, and their answers are likely dependent on the organization/mission. They include:

1. Level of detail. How many tasks/information requirements should be displayed?

2. Organizational scope: How many consumers should be included? Should there be a single display or a separate one for each consumer?

3. Display organization: Should the displays be organized by one of the categories of information provided, e.g., current tasks, or some other factor, such as consumer or priority of tasks?

- Display format: Should the display be text-based (as in the experiment), graphical, or a mixture? Should the display be an "interactive," computer-based interface or static?

- Other features: Potential features include highlighting of task and information priorities, alerting of changes to new information and providing other details about the consumer.

These issues need to be considered in the design of any "situation context display" and should be the focus of future research.

\section{Follow-on Work}

Situation Context Displays. Based on the results of the above experiments, two prototype displays that aimed at communicating situation context were developed. One communicated this information in a text-based interface and one communicated via a graphical interface. They were recently demonstrated and evaluated during an applied pilot experiment conducted in the Multi-Echelon Command and Control (MECC) Laboratory at the Naval Postgraduate School. These displays were used by teams of SMEs as they performed a collaboration/coordination task. Performance measures included speed and accuracy of communications, accuracy and relevance of exchanged information, and situation awareness, as well as a variety of subjective measures. Although only a pilot experiment, the data provided preliminary suggestions about changes to the prototype display. An example display based on these changes is shown in Figure 5. This display communicates information about the mission, organization, consumer task, information requirements and feedback with new information highlighted by diamonds, hyperlinks to more detail and visual linking to a map of the mission area. 


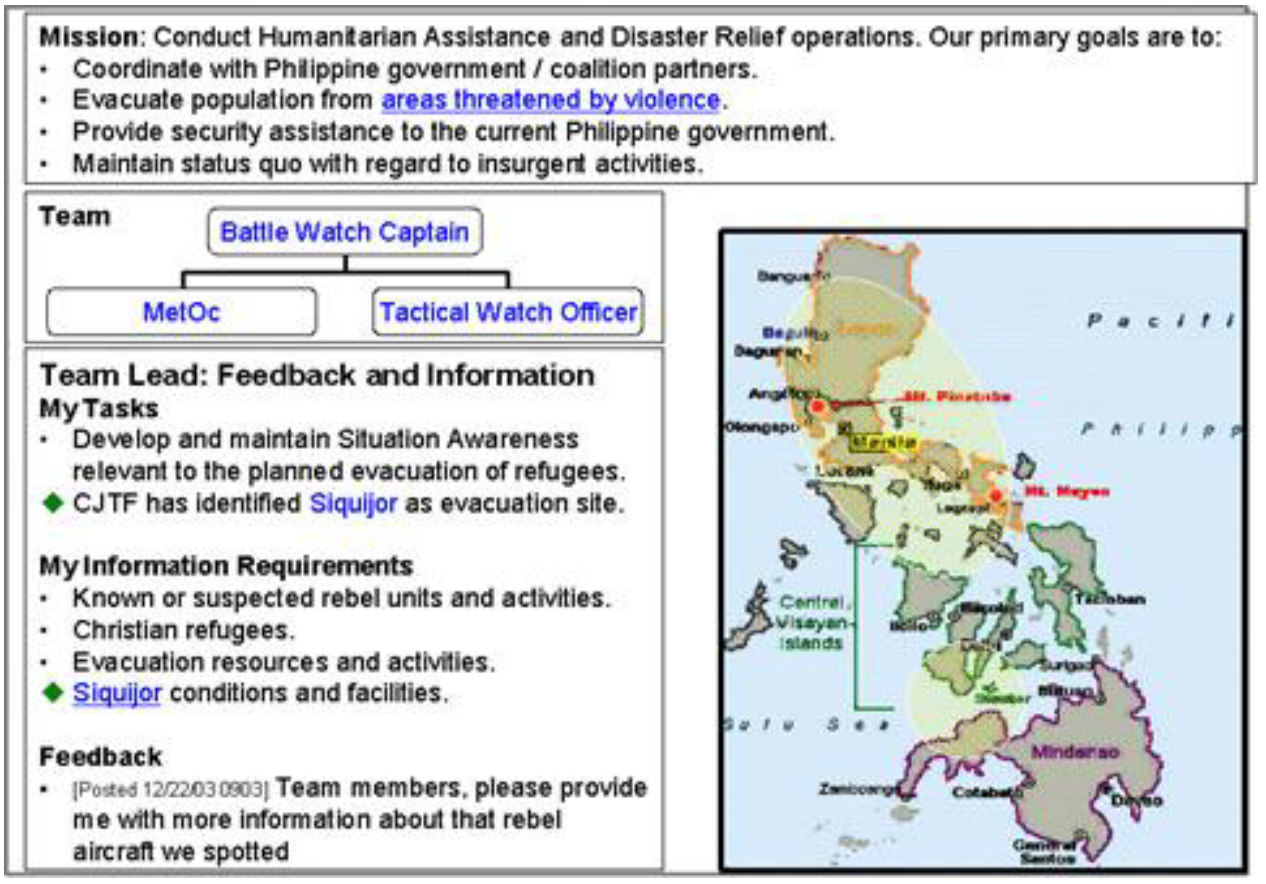

Figure 5. Example Situation Context Display.

Changes in situation context. One factor that has emerged from our previous cognitive task analyses and research is that both minor and major changes to mission objectives or producers' and consumers' organizational structure directly impact those with whom they share information and the kinds of information shared. Often, as change occurs, consumers have no easy way to notify producers of such changes, and no easy or effective way to provide feedback regarding the information that is shared. As a result, the overall efficiency and effectiveness of information exchange suffers. Future research will continue and extend our current findings, with a focus placed on understanding the effects of change on information exchange (e.g., to mission goals, organizational structures, and consumers' tasks and information requirements), and on the development of technologies and business rules to help manage the effects of such changes.

\section{References}

Caldwell, B. S., \& Everhart, N. C. (1998). Information flow and development of coordination in distributed supervisory control teams. International Journal of HumanComputer Interaction, 10, 51-70.

Cannon-Bowers, J. A., Salas, E., \& Converse, S. A. (1993). Shared mental models in expert team decision making. In: N. J. Castellan Jr., (Ed.), Individual and group decision making: Current issues in individual and group decision making (pp. 221-246). Hillsdale, NJ, Lawrence Erlbaum Associates.

Heacox, N. J., Gwynne, J. W., Kelly, R. T., \& Sander, S. I. (2000). Cultural variation in situation assessment: Influence of source credibility and rank status. (Technical Report No. 1829). San Diego, CA: SPAWAR Systems Center. 
Klimoski, R. J., \& Mohammed, S. (1994). Team mental model: Construct or metaphor? Journal of Management, 20, 403-437.

Mathieu, J. E., Goodwin, G. F., Heffner, T. S., Salas, E., \& Cannon-Bowers, J. A. (2000). The influence of shared mental models on team process and performance. Journal of Applied Psychology, 85, 273-283.

Milanovich, D. M., Driskell, J. E., Stout, R. J., \& Salas, E. (1998). Status and cockpit dynamics: A review and empirical study. Group Dynamics: Theory, Research, and Practice, 2, 155-167.

Moore, R. A., \& Averett, M. G. (1999). Identifying and Addressing User Needs: A Preliminary Report on the Command and Control Requirements for CJTF Staff. Proceedings of the 1999 Command \& Control Research \& Technology Symposium (pp. 403-420). Washington, D.C.: National Defense University.

Oonk, H. M., Schermerhorn, J. H., Glaser, D. N., \& Manes, D. I. (2003). The components of information exchange in dynamic collaborative environments. (Technical Report) San Diego, CA: Pacific Science \& Engineering Group.

Oonk, H. M., Smallman, H.S., \& Moore, R. A. (2001). Evaluating the usage, utility and usability of Web-Technologies to facilitate knowledge sharing. In Proceedings of the 2001 Command and Control Research and Technology Symposium, Annapolis, MD.

Rogers, J. H., Oonk, H.M, Moore, R. A., \& Morrison, J. M. (2002). The design, implementation and use of Web-technologies to facilitate knowledge sharing: A 'realworld' application. In Proceedings of the 2002 Command and Control Research and Technology Symposium, Monterey, CA.

Rouse, W. B., \& Morris, N. M. (1986). On looking into the black box: Prospects and limits in the search for mental models. Psychological Bulletin, 100, 349-363.

Salas, E., Cannon-Bowers, J. A., \& Blickensderfer, E. L. (1997). Enhancing reciprocity between training theory and practice: principles, guidelines, and specifications. In J. K. Ford, S. W. J. Kozlowski, K. Kraiger, E. Salas \& M. S. Teachout (Eds.), Improving training effectiveness in work organizations (pp.291-322). Mahwah, NJ: Lawrence Erlbaum Associates.

Shattuck, L. G., \& Woods, D. D. (1997). Communication of intent in distributed supervisory control systems. Proceedings of the Human Factors and Ergonomics Society 41st Annual Meeting. Santa Monica, CA: Human Factors Ergonomic Society.

Smallman, H.S., Oonk, H. M., \& Moore, R. A. (2001). Identifying Decision Maker Information Requirements for Knowledge-Centric Information Systems. In Proceedings of the 2001 Command and Control Research and Technology Symposium, Annapolis, MD. 